\title{
A COLLABORATIVE HIGHER EDUCATION INITIATIVE FOR LEADERSHIP DEVELOPMENT: LESSONS FOR KNOWLEDGE SHARING
}

\author{
R. Albertyn* \\ e-mail:rma@sun.ac.za

\section{Frick*} \\ e-mail: blf@sun.ac.za \\ *Department Curriculum Studies \\ Stellenbosch University \\ Stellenbosch, South Africa
}

\section{ABSTRACT}

The higher education sector needs to prepare youth for the fast changing innovative focused economy. Visionary leadership is needed to facilitate this knowledge transfer for novelty creation. A collaborative initiative could facilitate leadership development and foster knowledge sharing in this context. The initiative with three stakeholder groups started with an Interactive Qualitative Analysis exercise to identify needs and formulate a collaboration charter to ensure reciprocal benefits. A programme evaluation research design was applied three years after implementation using a logic-model framework. Process evaluation entailed collecting data from 103 questionnaires and 11 semi-structured interviews. Based on interpretation of data according to an integrated framework for sharing knowledge across boundaries, we identified three areas for further development: contextual knowledge, collaborative partnerships and common vision. Working collaboratively across institutional and knowledge boundaries towards a common vision could enhance leadership development and contribute to longer-term transformation and sustainable change in complex environments.

Keywords: higher education leadership development, knowledge sharing, collaboration, vocational education, process programme evaluation, institutional and knowledge boundaries.

\section{INTRODUCTION}

It is vital that leadership development efforts focus on skills needed to be responsive to the current macro- and micro-environmental challenges in any given context. Internationally, there are trends to increase participation in higher education, which calls for learning environments that match the needs and demands of the stakeholders while also addressing contextual challenges (Broek and Hake 2012). In the macro-context, James, Unwin and Guille (2013, 246) 
highlight the importance of knowledge, innovation and creativity for survival in the current competitive reality. Brown (2010) concurs and adds that many countries worldwide seem to be turning to innovation as a strategy for growth. The challenge posed for education researchers is to engage in the problem of how to enable learning for innovation (Editorial 2013). Insight into the 'how' may be provided by Howell and Annansingh $(2013,33)$ who say that without knowledge sharing amongst partners, organisations would constantly reinvent themselves with ways of leveraging past experience and expertise and thus avoid innovative practices.

Different higher education institutional systems with varying forms of expertise could benefit from collaboration to address the challenges in the context where they are situated (Edwards 2011). The macro-context of this study is thus higher education being responsive to training for the current workplace. In preparing the workforce to survive in the current competitive international arenas, higher education institutions may need to focus on new skills and ways of training or knowledge sharing to deal with these challenges. Thus, creating the space for this type of learning between and within the sectors in higher education in a collaborative way could be an important way to foster innovation. Furthermore, developing leaders for the educational context facing these challenges is important (Goldrick 2002; Singh 2004; Findlay, Spours, Steer, Coffield, Gregson and Hodgson 2007). Developing leadership skills at the interface amongst various stakeholders represent micro-contextual leadership issues, which may need to be enhanced. It would therefore be beneficial to explore the change and knowledge management in a leadership development process in a collaborative context as it could assist in providing guidelines for further development initiatives in education.

The context of the study reported on in this article is a collaborative project in response to the Technical Vocational Education and Training (TVET) college sector challenge for leadership development in the South African setting (see Akoojee, McGrath and Visser 2008; Cloete 2009; Stumpf, Papier, Needham and Nel 2009; Ngcwangu 2015). It was envisaged that capacity enhancement through collaborative leadership development, which bridges the higher education/TVET sector divide, could play a role in the long term improvement of the quality and sustainability of educational provision in the region (Sonn 2008; Nzimande 2010). The leadership development programme reported forms part of the leadership initiative under the auspices of the South African Further Education and Training Leadership Initiative (SAFETLI). The collaborators in the project are represented by SAFETLI, a consortium of three main stakeholders namely, TVET college leaders, a centre focused on higher and adult education at a South African university and a community college leadership programme at a North American university. 
The SAFETLI (2007) consortium proposed goals for the collaborative project. The short term development programme goals entailed presentation of six short course three-day workshops on leadership development based on identified needs (phase one). This first phase focused on leadership development skills of TVET leaders on the micro-context level as participants gained skills to lead more effectively in their educational environment. The longterm aim of the intervention was to provide an academic pathway for future leaders in the TVET sector building on the short courses on leadership. This long-term aim would build into macrocontext development as leaders embarking on doctoral studies would be gaining skills of creativity and make a novel contribution to knowledge creation and leadership in their context.

We applied process evaluation using a research design of programme evaluation to assess the strengths and weaknesses of the three-year-long leadership development initiative representing the first phase of the collaborative project. The purpose of this type of evaluation (process evaluation) was to provide insight into how the collaborative project was experienced after the first phase. It did not intend to ascertain the impact of the programme. Drawing on the findings of the programme evaluation, we highlight the knowledge sharing dynamics evident in this collaborative intervention. As the core business of higher education is the transfer and creation of knowledge, this study may provide an ideal site for exploring knowledge sharing, which could contribute to innovation. We propose that the insights gained regarding knowledge sharing through the collaborative effort amongst different stakeholder groups could provide guidelines for other leadership development projects.

We commence the article by reflecting on theoretical perspectives of the value of collaboration in a development project by clarifying concepts regarding the process of change through knowledge sharing, common vision and boundary partners. This is followed by details on the context of the study and the empirical programme evaluation conducted to identify strengths and weaknesses. The findings reflect elements of knowledge sharing for leadership development. Finally, we suggest areas of focus for knowledge management that could guide collaborative initiatives towards long-term transformation through developing leaders in this sector.

\section{THEORETICAL PERSPECTIVES}

Innovation or introducing new ways of doing things can help break the rut of 'lock-in' situations in which organisations get trapped (Maskell and Malmberg 2007, 606). It seems that there is no single best practice recipe in a process of innovation and knowledge creation in complex settings, because institutions are undergoing continual change and adjustment (Maskell and 
Malmberg 2007, 607-608). Practices need to emerge as the context changes. These changes call for a specific focus and special skills in leaders. The key elements for providing novel dimensions to enhance the interaction and learning experiences are common vision, collaboration and change. Before exploring the process of change, some perspectives on the common vision and collaborative partners are warranted.

\section{Focus on the common vision}

Special competencies are necessary for leaders in complex environments with multiple stakeholders. It is important to develop common meaning as a way to address differences in various sites in a system (Carlile 2004, 559). The focus on the common meaning and vision works to diffuse power and truth dialectics, which place power and truth in the hands of one powerful partner in the relationship. Furthermore, the multiple perspectives may be enriching and serve to provide a more novel solution to the challenges in the system. Edwards (2011, 33, 37) refers to this as 'common knowledge' or 'common understandings' and she suggests that this is an emotional driver of activity which is identified by asking participants: 'what matters?' to them.

Engeström (2001, 134) refers to the common mission as the 'object of activity' that is the motive for the endeavour in the system. Carlile $(2004,559)$ notes the importance of holding onto a common meaning when differences arise and that developing this common meaning is a 'process of negotiating and defining common interests'. Leaders in organisations need to develop these kinds of sensitivities and skills. These competencies include providing direction (visionary leaders), assuring alignment (organised leaders), building commitment (inspirational, empowering leaders) and facing challenges (being a resourceful problem-solver) (Risher and Stopper 2002).

\section{Collaboration between partners}

The expertise of various role-players or boundary partners can be harnessed in leadership development ventures aimed at enabling leaders to learn to be more effective and innovative. Each boundary partner in the collaboration has a unique skill set and contribution to bring to the learning context. Edwards $(2011,34)$ refers to this collaboration as 'relational agency' when working together to solve complex problems, such as leadership development in the TVET sector.

Relational agency implies that all parties recognise distinctive expertise that varies across settings. Together with their individual expertise, these partners bring their relational expertise 
that enriches an intervention. In addition, relational agency is the capacity to work with others to 'strengthen purposeful responses to complex problems' (Edwards 2011, 34). Collaboration thus appears to be a way to enhance the process of learning in complex settings. Social interaction that focuses on collaboration, cooperation and exchange of views in the joint search for knowledge is necessary (Bartlett and Elliot 2008; Sabourin 2013). Worthen (2011, 540) argues that learning happens when, due to the dialectical relationships between the parts, the power balances change and new potential for action emerge and are mobilised.

In a collaborative project, there are boundary spanners who build bridges between constituencies by occupying positions of dual membership in the system. Boundary spanning is a complex set of individual and organisational level activities in two domains: task orientation and social closeness (Weerts and Sandmann 2010, 638). McMillan (2009, 50) refers to the agents as those who help participants by making new connections across activity systems and in so doing facilitate new learning. Sabourin (2013) points out the importance of cooperation, and more specifically, the reciprocal relationship in adult education, where benefits and values are shared. The interaction also represents localised learning, as the process includes interactive knowledge creation, acquisition and exchange, which are in some ways local in character (Maskell and Malmberg 2007, 607). To a certain extent, there is the added benefit of interaction through the gleaning of information, gossip and news through just being part of the interaction (Gertler 2003, in Maskell and Malmberg 2007, 607). This is referred to by Hall $(2009,11)$ as a 'burst of creativity' or by Storper and Venables (2004, in Maskell and Malmberg 2007, 607) as a 'local buzz'. The collaborative project, purposively aimed at leadership development, has the potential to provide this focus.

\section{Process of change}

Sustainable change through knowledge sharing in an innovative learning process involves iteration and interaction between individuals and society on a deeper level of engagement. McWilliam (2013, xvii) states that the 'habits of deep and sustained engagement in learning (and unlearning)' are important for participation in the complex global environment. For sustained development in this context, Guile and Griffiths (2001) agree that greater depth of learning may be needed rather than just the specifics of practice or superficial solving of problems. Interactive learning processes can result in innovation, and therefore training seems to move to higher levels of learning where the 'unintended and unforeseen can emerge in different interactional encounters rather than predetermining the set of skills needed' (Editorial 2013, 278). A focused collaborative development project with short- and longer-term goals has 
the potential to facilitate this kind of learning.

There often is, however, an aversion to change and challenge as contended by McWilliam (2013, vii). Sometimes change needs to be mediated when there is resistance to break through the established routines where individuals, institutions and communities at times prefer to operate. Resistance may be situated in any of the sites within a system. We use the integrative framework of Carlile (2004, 558-559) for managing knowledge across boundaries, to explain the different levels of knowledge that are necessary to facilitate change in a collaborative setting across boundaries

Carlile draws on the work of Shannon and Weaver (1949, as cited in Carlile 2004, 557) and refers to three boundaries, namely syntactic, semantic and pragmatic boundaries. Carlile's model is applicable in the organisational context but resonates with the work of Biesta (2012) who distinguishes between three domains for educational purpose: qualification, socialisation and subjectification. In Carlile's model, the boundaries are placed in an inverted pyramid with the role players who are interacting placed on both sides of the pyramid. As both actors move up the pyramid, knowledge migrates from the 'known' to 'increasing novelty'. The types of boundaries and the boundary capabilities frame the three levels. Carlile (2004) points out that in syntactic or information-processing level of knowledge, transfer is usually the least problematic. The condition under which this takes place is generally quite stable and the knowledge is relatively known and can be viewed as common knowledge.

On the semantic or interpretive boundary level for translating knowledge, there is increased novelty, which makes some differences unclear and some meaning ambiguous. Usually in this process, shared meanings are negotiated. At this stage, the role of brokers may often be needed to enable the flow of knowledge - referred to by Weerts and Sandmann (2010) as the boundary spanners. Carlile (2004) also mentions the role of communities of practice in helping to develop shared meaning. Negotiation skills may be needed at this stage.

The transition to a pragmatic or political boundary for transforming knowledge occurs when the novel idea results in different interests among actors that have to be resolved. This level resonates with Ranciére's notion of emancipation as a process of subjectification, that is, of becoming a political subject (Ranciére 2003, as cited in Biesta 2012). In this case, the costs of adopting the novel solution may be high for both parties and may result in conflict in the process of producing knowledge. According to Carlile (2004), at this level, actors must be prepared to represent current and more novel forms of knowledge, learning about their consequences and transforming their domain specific knowledge accordingly. The knowledge that emerges is a mixture of transformed knowledge based on what is cognitively valued and 
the knowledge, which has been deemed to be still of consequence given the presence of the novelty.

The process of knowledge sharing from the 'known' to 'novelty' is challenging. Meyer and Land (2005) refer to the resistance, which often takes place at a boundary, and calls this a liminal space where the individual may feel stuck, as they need to negotiate the new learning space. Carlile (2004) refers to the importance of developing a common vision to help with the movement of knowledge across boundaries (see also Engeström 2001; Edwards 2011). A common vision may provide a fruitful focus when the context of learning is complex and challenging.

\section{THE CONTEXT: PROCESS OF DEVELOPMENT OF THE TVET LEADERSHIP PROGRAMME}

The collaborative initiative reported in this article was an outcome of a planning conference, which brought together three stakeholder groups who were the collaborative partners in this project. The founding institutions included eight participating TVET colleges, the South African and the North American higher educational institutional (HEI) boundary partners. The initiation of the partnership was in response to the complexity of issues in the TVET sector and the need for leadership development in this sector. Each of the role-players brought relevant expertise and resources to the partnership in line with the thinking of Edwards (2011) regarding relational expertise and agency. The partners have various forms of academic expertise in higher education and leadership development. Interactive Qualitative Analysis (IQA) was the data collection tool (Northcutt and McCoy 2004) used to identify the issues facing TVET leaders who attended the planning workshop. The three partners collaboratively worked to formulate short- and long-term goals based on the issues identified.

The long-term aim of the intervention was to provide an academic pathway for future leaders in the TVET sector. The underlying rationale behind this aim, that an immersion in academic debate through further study may enhance the leadership capacity in the sector, is supported by Duvall (2003) and Breier and Mabizela (2008). This long-term aim is not the focus of this article. We conducted process evaluation to access strengths and weaknesses of the short-term goal of the collaborative project (first phase). To accomplish the short-term aims, the issues identified during IQA were employed to plan collaboratively the content for various short courses to initiate debate in the TVET sector and concurrently develop leadership. The rationale for the short course is that it is important to develop the theory-based knowledge to higher levels to complement their existing relevant professional skills that reflect the syntactic 
or knowledge transfer level of Carlile (2004). In building on the common knowledge in the short course workshop, the emerging leaders would learn within their communities of practice (Lave and Wenger 1991). This combined approach in the short term reflects the first two levels of knowledge sharing, namely syntactic and semantic levels (Carlile 2004). By developing leaders in the TVET sector and by them being involved in accredited short courses (phase one), they could build an academic pathway to higher qualifications in the future (phase two).

The first short course accredited to fit into the academic pathway was designed collaboratively. The three-day short course focused on aspects of leadership and management in the TVET sector, concepts of leadership and management, models of leadership and management, realities of the TVET sector, emotional intelligence and personal aspects of leadership and management, the role in sustaining improvement in the TVET sector, and values, qualities and power in TVET leadership. There was collaboration in facilitating the short courses over a two-year period and were co-presented by a TVET leader, who was identified at the planning conference, a lecturer from the local university and the North America university representative in South Africa who provided input on occasion.

\section{THE RESEARCH: IDENTIFICATION OF STRENGTHS AND WEAKNESS OF THE IMPLEMENTED STRATEGY}

Programme evaluation as research design was applied and a theory-driven evaluation approach was used to assess how effectually the programme functioned and the extent to which the first phase of the TVET leadership collaboration had achieved what it intended to achieve (Rossi, Lipsey and Freeman 2004, 56). The logic model served as a guide for data collection as indicators are aligned with the aims and objectives of the programme as set out by the SAFETLI collaborative partners (Chen 2005, 34). Both qualitative and quantitative research methods were used to collect data (Babbie and Mouton 1998; Cresswell 2009). Document analysis of SAFETLI (2007) documentation was applied for the formulation of the logic model. The structured feedback questionnaire from 103 participants was received directly after each of the six short courses. Semi-structured telephonic and face-to-face interviews were conducted with three representatives of each of the three stakeholder groups and with 11 TVET short course participants. Data was analysed using the steps of Henning, Van Rensburg and Smit (2004), namely reading, open coding, categorising and grouping data into themes. As anonymity was assured, we report the data referring to participants using alphabetical letters (A, B, C, to S). 


\section{THE FINDINGS: ELEMENTS FOR LEADERSHIP CAPACITY ENHANCEMENT}

The findings of the process programme evaluation of the first phase of the leadership project reveal partners’ perceptions, learning, application and challenges. Process evaluation serves to identify strengths and weaknesses, which provide practical value to the collaborative partners for improvement of the programme. Of academic interest is the insight into the elements of knowledge sharing through a collaborative leadership initiative. Interpreting the data in the light of this learning element could provide insights on facilitating leadership development in other contexts.

\section{Perceptions}

Positive perceptions are often found when courses are aligned to the learning needs of adult participants (Knowles 1984). In the case of this study, examples of relevance to the participants' learning needs and context are reflected in the following statements:

Short course is relevant. It helps one with better management. (M)

I am now a principal. I come into contact with a lot more of these things ... the type of information that you need. I must know how to manage people. (C)

It seems that the group activities in the short courses contributed to positive perceptions of the programme. The groups were diverse. There were people from various regions in South Africa, various culture and racial groupings and on different management levels. Networking and teambuilding was experienced and learning was enhanced through contact with others in the group. Sabourin (2013) acknowledges the value of knowledge sharing through social interaction. There were some participants who attended the short course as part of a group from the same college, which was viewed as being a negative aspect. The benefit of learning from others in other colleges may have been hampered thus hindering networking and learning through diversity. This comment may indicate a readiness to learn from others or benefit from relational expertise (Edwards 2011) outside of their context in an attempt to move to innovation to help break the rut of 'lock-in', in which organisations get trapped (Maskell and Malmberg 2007).

According to the participants, the facilitators were well prepared and professional, and their expertise, knowledge and academic input were valued. This was verified in the postevaluation questionnaire, where the capacity of the facilitator was rated highest (mean score 4.8; where 5=excellent on the 5-point Likert scale). The facilitators' approach to learning and the way they engaged with the course participants was valued: 'How they got everything across; 
how they got everybody involved' $(\mathrm{H})$. This indicated that the philosophy of collaborative learning was included in the facilitation of the programme, which would engage the participants in experiential learning about the benefits of collaboration. The following quotations illustrate the value of collaborative learning in the group setting:

One was busy all the time while brainstorming about the various activities and things. (S) ... concrete examples used .... It was much more hands on ... was not bored in the three days that I was there. (C)

The TVET facilitator noted that the 'IQA is a therapeutic experience as we provide an ear for the participants' (A). The IQA approach could be an example of Carlile's semantic or interpretive boundary where knowledge needs to be translated in a collaborative environment (2004). Bartlett and Elliot (2008) note the value of social engagement for change and learning. The IQA exercise and the short course contributed to creating the local 'buzz' around development by including role players in contextual leadership discussions (Maskell and Malmberg 2007). The facilitators also seemed to have a good rapport with the participants and they were in touch with the field and the participants: 'They handled issues that we deal with every day’ (R).

The participants felt that the facilitator's involvement in the sector itself increased his credibility.

... the facilitator, because he comes out of the college sector, this made that he and us could relate to one other .... We could find one other .... He knew precisely what we were talking about and we knew what he was talking about. (S)

These comments reflect the common knowledge of the syntactic level of Carlile (2004). However, one respondent was negative about the style of the facilitator.

It was just moving through; put up your hand; pick you up and then again moving through, moving, moving. You had a little brainstorm on this, it moves at quite a pace. They actually rushed through those notes and tried to do as much as they could. $(\mathrm{G})$

This comment indicates that not all participants perceive what may be seen as common knowledge equally. McMillan (2009) refers to the responsibilities of knowledge brokers to make new connections across activity systems to facilitate new learning. Furthermore, one respondent (J) felt that the non-South African presenter was not as 'clued up' about the context. This comment illustrates the local character in localised learning (Maskell and Malmberg 2007). Therefore, establishing the common knowledge in partners in a collaborative project 
(Carlile 2004) is important. Negative comments also may be a mechanism to equalise power imbalances amongst role-players and provide food for critical reflection for facilitators.

Thus the short course participants' perceptions of the learning experience and the facilitator revealed that they found the course to be relevant, well organised and that groups attending and interacting improved their perception of the leadership initiative.

\section{Learning}

Learning is constructed by the learner rather than received from the teacher (Jarvis, Holford and Griffin 1998). Application to the participants' own context was a key element as is illustrated by the following two comments:

It was a good reflection on things that I know and to know what others are experiencing on the ground; and where they experience problems and that one can come back and check with your own staff where those things exist and try to find a way to solve it. (E)

The whole process of leadership and how you see yourself, your involvement, the confidence, the delegation to other people and the channelling to other people. It was very spot on for me. (M)

Learning took place on three levels: personal learning, context related and workplace learning. Personal learning was infused in the course learning, for example:

A person learns more about yourself .... There you realise things that you really were not aware of. (A)

The participants felt that having to engage in context related aspects, like the policy, in the short course was beneficial, as it is not something that they would have done themselves. One person stated:

We went through the FET Act and things like that .... I think maybe reinforcing would be a better word. (V)

There was one person who was critical of the course content and this should be noted:

You know they advertised it this way that there was a critical look at how a ... college should be managed and things about leadership. It was not that. (G)

This comment needs to be addressed as it reflects a learning need to find novel ways to deal with the complex environment of these colleges. The effect of the changes in the TVET sector could result in low morale and insecurity of the employees in the sector (Akoojee et al. 2008). There is a need for critical engagement on this topic. It seemed as if the participants had 
different expectations. There were those who needed to go through the knowledge sharing process at a syntactic level, but there were those who wanted to engage critically at higher levels. Facilitators need to be aware of the levels and be sensitive to the needs of the group in this regard, if the aim is to move them to novel thinking (Carlile 2004).

What the participants learned in the short course influenced their work related knowledge and strategic thinking:

... thinking more towards the strategic plan of the institution .... Just look at the strategy and see everything against the strategy. (E)

Good to hear again of the different approaches or types of leaders ... realise again what type of leadership I am busy applying and what I must take note of that is also maybe still important. (S)

These comments reflect moving to translating knowledge at the semantic or interpretive boundary. It appears as if the basic common knowledge is the foundation for moving up the pyramid towards novel thinking. Building in activities to establish the transfer knowledge may be necessary before participants can move to translating knowledge at the interpretive boundary (Carlile 2004). The link between relevance to the personal, context- and work-related aspects and what they learn is clearly important in the evaluation of a learning programme.

\section{Application}

Application indicates whether the learning that took place resulted in changed behaviour. Participants commented positively regarding application, for example:

I had a strategic training session where I immediately changed the whole college strategic planning and gave it more focus. (M)

It is something that I am more aware of now ... that I am really trying and hand tasks to people and then let them run with it and then try not to stand over them. It definitely has allowed my management team to flourish .... I think it also has helped the whole team. (V)

The last comment seems to illustrate that the participant has learned experientially (Kolb 1984) and is applying social interaction to foster learning as experienced in the short courses. However, one participant was negative and felt that he did not take anything back to his office that he could apply. In this case, the facilitators need to reflect critically to ensure that there are benefits for all participants. There needs to be further opportunities for application in the work place to ensure sustained change and emancipation rather than just adaptation noted by Biesta (2012). 


\section{Challenges}

The challenges in the higher education context provide impetus for learning. The TVET facilitator commented that 'the changing environment in the TVET/HE sector is a process that they find insecure and has an influence on the sector and their morale' (A). The participants also noted the changing TVET sector (respondent B) and the fact that leaders need to adjust.

Akoojee et al. (2008) note this insecurity in the TVET sector. Due to complexity in the sector, leaders will require a different skill set (Broek and Hake 2012; James et al. 2013). The new requirements and structures in the sector will influence the way that leaders will need to operate. One participant felt that the changes in policy would affect the course content and how leaders are trained in the sector:

Therefore, I suggest that they go and look again at what their focus is and who the target market will be in TVET colleges in the next 5 years. (M)

This reflects cognisance of the pragmatic or political boundary for transforming knowledge of Carlile (2004). Leadership development initiatives may thus need to be adjusted to prepare leaders adequately within the changing and new policy context to be more innovative in the face of the conflicts that novelty demands. One participant suggested that certain topics be considered for inclusion in the content of the leadership course:

... organisational intelligence. Running your organisation intelligently ... have effective structures in place. $(G)$

This comment is evidence of the need for innovation, creativity and knowledge creation (James et al. 2013).

The problem of dependency within the TVETC sector was mentioned twice. One comment concerned funding, and how it relates to interest in training:

... often everyone stands with open hands, they only want to do things if it is for free .... If there is big funding, then there is an incredible interest. (M)

The second comment by the TVET facilitator relates to the attitude and level of thinking of the participants:

The problem comes in when they have to ... speak of solutions, they really battle and the solutions they suggest are not on a high level. (A)

Thus, there is the need to encourage knowledge at the higher level of transforming knowledge 
(Carlile 2004), as this could lead to sustainable change in this sector (Mezirow 2000). The problem of dependency and the manifestation thereof would need to be acknowledged and the planning of course content and activities should actively aim to develop independence and critical reflection.

\section{CONCLUSION: FOCUS FOR KNOWLEDGE MANAGEMENT IN LEADERSHIP DEVELOPMENT INITIATIVES}

Insights into the strengths and weaknesses of the collaborative leadership initiative were gleaned through the programme evaluation design in the study reported in this article. These insights in turn point to elements of knowledge sharing in a collaborative project in this complex educational environment. Based on findings from the programme evaluation, there were positive perceptions of the course in terms of the learning experience, its relevance, organisation and the groups attending the course. In a sense, this positive response contributed to creating the 'buzz' in the local context (Maskell and Malmberg 2007). The participants had a positive perception of the skills of the facilitators as they focused on the individual and their needs, and the planned activities were applicable to the context of the participants.

Application was evidenced on three levels, namely personal, context-related and workrelated, suggesting the success of the intervention on these levels. Interpretation based on the theoretical framework of Carlile (2004) helped identify what still needs to be done to assist the leaders in developing knowledge creation in the complex higher education setting. It seems as if the short-term goals were achieved in developing knowledge through the short courses. Group learning stood out as being beneficial to this learning process. More needs to be done to help participants develop higher-level skills to lead in the complex environment of the TVET sector.

Knowledge sharing takes place across boundaries when working collaboratively to fulfil a common vision in a complex environment. The diverse groups from different regions seemed to encourage this knowledge sharing process. We propose that key elements distilled from the theoretical perspectives and the findings of the programme evaluation study could serve as a guide to facilitators of learning. We identified three key elements and identify both the learning and the facilitation of learning for each:

- Contextual knowledge: This level corresponds with Carlile's (2004) level of the 'known' and reflects the common knowledge, which emerges from the context of the initiative. Learning at this micro-level is usually not problematic as it relates to the context of the role-players. The onus on the facilitators is to familiarise themselves with the context, the 
needs of the participants and relevant subject content. Engagement in the local context can also help to stimulate interest in the initiative and to create a local 'buzz'. Reciprocal benefits need to be acknowledged.

- Collaborative partnerships: The key element at the interface is collaboration and shared learning with mutual benefits to all role-players. Learning activities and application possibilities could focus on group activities to learn experientially about collaboration and the benefits of relational expertise and agency. There is a need to move out of the educational silos represented by varying forms of higher education and focus on working together to address problems. Relative power dynamics need to be balanced with a focus on reciprocity. We need to create arenas for dialogue to solve relevant contextual issues. Collaborative partners or 'boundary spanners' all need to work in synergy to have maximal impact in the sector.

- Common vision: The key focus on this higher level of knowledge sharing is innovation within the context, and on ensuring a common vision for the environment. As no easy solution may be apparent at this level of 'novelty creation', there may be facilitation challenges for negotiated learning. There may be times of disquiet and tension. The facilitators may need to stimulate creative conflict situations where novel ideas can be distilled through critical reflection for transformation. New skills may be needed to facilitate this process. If the guiding focus is on the collective vision, collaborative partners may be sustained to persevere towards novelty and innovation.

Developing leaders who value novelty creation and innovation is a long-term process. Facilitating this learning may need to be scaffolded to facilitate effective sharing of knowledge. There needs to be continual assessment of the level of knowledge transfer being experienced through collaborative efforts to make adaptations to the style of facilitation to move the participants toward novelty creation. The process programme evaluation conducted during the course of the intervention provided guidelines for collaborative partners for revision and improvement. Impact evaluations could assess the long-term impact. Continued research could identify strategies for improved collaboration among boundary partners. Further development of collaborative higher education leadership initiatives is imperative against the background of the challenges facing leaders in complex environments. If collaborative partners work towards a common vision and scaffold the boundary knowledge sharing, despite creative tensions in the shared learning experiences, then learning could lead to transformation and innovation in the sector. 


\section{REFERENCES}

Akoojee, S., S. McGrath and M. Visser. 2008. Further education and training colleges. In Human resources development review, ed. A. Kraak and K. Press, 254-277. Cape Town: Human Sciences Research Council (HSRC) Press.

Babbie, E. and J. Mouton. 1998. The practice of social research. Cape Town: Oxford University Press.

Bartlett, B. and S. Elliott. 2008. The contributions of educational psychology to school psychology. In The handbook of school psychology, ed. T. Gutkin and C. Reynolds, 65-83. $6^{\text {th }}$ ed. Mahwah, NJ: Lawrence Erlbaum and Associates.

Biesta, G. 2012. Have lifelong learning and emancipation still something to say to each other? Studies in the Education of Adults 449(1): 5-20.

Breier, M. and M. Mabizela. 2008. Higher education. In Human resources development review, ed. A. Kraak and K. Press, 278-299. Cape Town: Human Sciences Research Council Press.

Broek, S. and B. Hake. 2012. Increasing participation of adults in higher education: Factors for successful policies. International Journal of Lifelong Education 31(4): 397-417.

Brown, L. 2010. Balancing risk and innovation to improve social work practice. British Journal of Social Work 40(4): 1211-1228.

Carlile, P. R. 2004. Transferring, translating and transforming: An integrative framework of managing knowledge across boundaries. Organization Science 15(5): 555-568.

Chen, H. 2005. Practical program evaluation. Los Angeles, CA: Sage Publications.

Cloete, N., ed. 2009. Responding to the educational needs of post-school youth: Determining the scope of the problems and developing a capacity-building model. Wynberg: Centre for Higher Education Transformation.

Cresswell, J. 2009. Research design. $3^{\text {rd }}$ ed. Los Angeles, CA: Sage Publications.

Duvall, B. 2003. The role of universities in leadership development. New Direction for Community Colleges 123: 63-71.

Editorial. 2013. Lifelong learning, adult education and the 'innovation spirit'. International Journal for Lifelong Education 32(3): 227-279.

Edwards, A. 2011. Building common knowledge at the boundaries between professional practices: Relational agency and relational expertise in systems of distributed expertise. International Journal of Educational Research 50(1): 33-39.

Engeström, Y. 2001. Expansive learning at work: Toward an activity theoretical reconceptualization. Journal of Work and Education 14(1): 133-134.

Findlay, I., K. Spours, R. Steer, F. Coffield, M. Gregson and A. Hodgson. 2007. 'The heart of what we do': Policies on teaching, learning and assessment in the learning and skills sector. Journal of Vocational Education and Training 59(2): 137-153.

Goldrick, L. 2002. Improving teacher evaluation to improve teaching quality: Issue brief. Washington DC: NGA Center for Best Practices, Education Policy Studies Division.

Guile, D. and T. Griffiths. 2001. Learning through work experience. Journal of Education and Work 14(1): 114-131.

Hall, M. 2009. Transgressive partnerships: Community engagement in a South African University. Gateways: International Journal of Community Research and Engagement 2: 1-17.

Henning, E., W. van Rensburg and B. Smit. 2004. Finding your way in qualitative research. Pretoria: Van Schaik.

Howell, K. and F. Annansingh. 2013. Knowledge generation and sharing in UK universities: A tale of two cultures? International Journal of Information Management 33(1): 32-39.

James, L., D. Guile and L. Unwin. 2013. Learning and innovation in the knowledge based economy: 
Beyond clusters and qualifications. Journal of Education and Work 26(3): 243-266.

Jarvis, P., J. Holford and C. Griffin. 1998. The theory and practice of learning. London: Kogan Page.

Knowles, M. 1984. Andragogy in practice. San Francisco, CA: Jossey-Bass.

Kolb, D. 1984. Experiential learning: Experience as the source of learning and development. Englewood Cliffs, NJ: Prentice Hall.

Lave, J. and E. Wenger. 1991. Situated learning: Legitimate peripheral participation. Cambridge: Cambridge University Press.

Maskell, P. and A. Malmberg. 2007. Myopia, knowledge development and cluster evolution. Journal of Economics Geography 7(5): 603-618.

McMillan, J. 2009. Through an activity lens: Conceptualising service learning as 'boundary work'. Gateways: International Journal of Community Research and Engagement 2: 39-60.

McWilliam, E. 2013. Foreword. In Reshaping doctoral education: Programs, pedagogies, curriculum, ed. A. Lee and S. Danby, xxiii-xxvii. London: Routledge.

Meyer, J. and R. Land. 2005. Threshold concepts and troublesome knowledge (2): Epistemological considerations and a conceptual framework for teaching and learning. Higher Education 49(3): 373-388.

Mezirow, J. 2000. Learning as transformation. San Francisco, CA: Jossey-Bass.

Ngcwangu, S. 2015. The ideological underpinnings of World Bank TVET policy: Implications of the influence of human capital theory on South African TVET policy. Education as Change 19(3): 24-45.

Northcutt, N. and D. McCoy. 2004. Interactive qualitative analysis: A systems method for qualitative research. Thousand Oaks, CA: Sage Publications.

Nzimande, B. 2010. Address by the Minister of Education at the Further Education and Training Colleges Summit, Birchwood Hotel. http://www.jet.org.za (accessed 23 August 2012).

Risher, H. and W. Stopper. 2002. Reflections on the state of leadership and leadership development. Human Resource Planning 25(2): 4-10.

Rossi, P., M. Lipsey and H. Freeman. 2004. Evaluation: A systematic approach. Los Angeles, CA: Sage Publications.

Sabourin, E. 2013. Education, gift and reciprocity: A preliminary discussion. International Journal of Lifelong Education 32(3): 301-317.

SAFETLI see The South African Further Education and Training Leadership Initiative.

Singh, M. 2004. Improving teaching and learning resources. In Resource No. 6: Staff development and self-evaluation of teaching, ed. CHE. http://www.heqc.co.za (accessed 23 August 2012).

Sonn, R. 2008. Poverty, unemployment and education: Strategies to address the disservice of modern development. In Education and poverty reduction strategies, ed. S. Maile, 182-198. Cape Town: Human Sciences Research Council (HSRC) Press.

Stumpf, R., J. Papier, S. Needham and H. Nel. 2009. Increasing educational opportunities for post NQF Level 4 learners through the FET college sector. http://chet.org.za/files/uploads/reports/ Report_CHET_Youth_Final_Short_Report.pdf (accessed 23 August 2012).

The South African Further Education and Training Leadership Initiative. 2007. Draft Charter, December. Stellenbosch: Centre for Higher and Adult Education.

Weerts, D. J. and L. R. Sandmann. 2010. Community engagement and boundary-spanning roles at research universities. Journal of Higher Education 81(6): 632-657.

Worthen, H. 2011. CHAT learning theory for labour educators: Work process knowledge, activity theory and communities of practice. Labour Studies Journal 36(4): 538-544. 